The University of Maine

DigitalCommons@UMaine

Publications

Senator George J. Mitchell Center for Sustainability

Solutions

$5-2014$

\title{
Interdisciplinarity and Actionable Science: Exploring the Generative Potential in Difference
}

Bridie McGreavy

University of Maine, bridie.mcgreavy@maine.edu

Linda Silka

University of Maine, lndsilka7@gmail.com

Laura Lindenfeld

University of Maine, laura.a.lindenfeld@maine.edu

Follow this and additional works at: https://digitalcommons.library.umaine.edu/ mitchellcenter_pubs

Part of the Civic and Community Engagement Commons, and the Sustainability Commons

\section{Repository Citation}

McGreavy, Bridie; Silka, Linda; and Lindenfeld, Laura, "Interdisciplinarity and Actionable Science: Exploring the Generative Potential in Difference" (2014). Publications. 88.

https://digitalcommons.library.umaine.edu/mitchellcenter_pubs/88

This Article is brought to you for free and open access by DigitalCommons@UMaine. It has been accepted for inclusion in Publications by an authorized administrator of DigitalCommons@UMaine. For more information, please contact um.library.technical.services@maine.edu. 


\section{Interdisciplinarity and Actionable Science: Exploring the Generative Potential in Difference}

Bridie McGreavy

New England Sustainability Consortium, Senator George J. Mitchell Center, University of Maine, Orono, ME, USA

Linda Silka

School of Economics, Margaret Chase Smith Policy Center, Orono, ME, USA

Laura Lindenfeld

Department of Communication and Journalism, University of Maine, Margaret Chase Smith Policy Center, Orono, ME, USA

Address correspondence to Bridie McGreavy, Ph.D. Communication and Sustainability Science, New England Sustainability Consortium, University of Maine, Senator George J. Mitchell Center, Norman Smith Hall, Orono, ME 04469. E-mail: bridie.mcgreavy@maine.edu 
ABSTRACT

Community practice and actionable science share a commitment to solving complex problems to promote sustainability. Collective abilities to address these types of problems rely on interdisciplinary collaborations that also offer unique challenges. In this case study of a statewide interdisciplinary setting, we focus on key methodological differences related to problem identification, stakeholder involvement, competing research paradigms, and orientations towards communication. We argue the generative potential in interdisciplinarity is enhanced through sustained effort and attention to difference; acceptance of the ethical responsibility to reflect critically on power in shared decision making spaces; and strategic interventions to continually promote and improve learning.

KEYWORDS: interdisciplinarity, community practice, sustainability science, collaboration, university-community partnerships, case study 
INTRODUCTION

Complex problems are the starting point for engaged research in community practice and actionable science (Butterfield \& Korazim-Kõrösy, 2008; Palmer, 2012). Deeply entangled social, ecological, and economic problems have been described as "wicked" due to their cross-scale interactions, indefinite thresholds, and apparent intractability (Kreuter, Rosa, Howze, \& Baldwin, 2004, p. 442). In their discussion of the current context of community practice within the United States, Weil, Reisch, and Ohmer (2013) highlighted some of the wickedness of problems issuing from globalization. These include persistent and increasing income disparities; the social, political, and economic consequences of environmental degradation; and global health problems related to water pollution and inadequate waste treatment systems, among many others. A key strategy in trying to solve these and other wicked problems is to strengthen capacities within civil society for informed and sustainable actions (Reisch, 2012; Weil et al., 2013). Community practice and actionable science share the commitment to interdisciplinarity approaches to grow capacity for change across scales and in diverse contexts (Bayne-Smith, Mizrahi, \& Garcia, 2008; Gamble \& Hoff, 2013; Palmer, 2012).

How does interdisciplinarity unfold in contexts characterized by wicked problems? What kinds of differences emerge and how do these affect capacity building? We address these questions by drawing from over 3 years of research with Maine's Sustainability Solutions Initiative (SSI), a statewide project that uses inter- and 
transdisciplinary approaches to solve complex problems related to climate and energy, urban development, and water resource management. We argue that attending to differences in collaborations allows us to grapple with some of the wickedness in seemingly intractable situations and create possibilities for new learning and innovative solutions. Although there are myriad differences that are possible in interdisciplinary collaborations, such as divergent ontologies, epistemologies, value systems, attitudes, status, and more, we restrict our focus to four key methodological differences. We start here because these more tangible anchor points enable the development of mutual understanding, which may then open deeper discussions about less tangible but no less important worldviews and attendant attitudes, values, and epistemologies (Dewulf, François, Pahl-Wostl, \& Taillieu, 2007). First, we describe differences in research framing, especially as it relates to computer-based modeling. Second, we highlight differences in how interdisciplinary researchers make decisions about who should be involved in research processes and how to involve them. Third, we attend to differences in disciplinary methods and guiding research paradigms and focus on the implications for power in knowledge production. Fourth and finally, we discuss differences in how to communicate knowledge derived from research. We conclude by working with a metaphor of making a meal together to recommend specific strategies to promote the creative potential emergent from difference. These include attending to decision making and power; using insights from boundary literatures to develop graduate courses and other strategic learning opportunities; and initiating writing projects that allow collaborators to explore divergent perspectives. 
In the following section, we engage the productive tension in interdisciplinarity in which there is a simultaneous drive toward unity - of the research team, community, and other forms of social organization - that also seeks to maintain diversity (Gutiérrez, Lewis, Dessel, \& Spencer, 2013). Sustained critical inquiry within inter- and transdisciplinary processes can help maintain and promote learning from difference (McGreavy, Hutchins, Smith, Lindenfeld, \& Silka, 2013). We demonstrate this mode of inquiry and attendant strategies that enable it in our analysis and discussion of SSI as a case study.

\section{CRITICAL INQUIRY IN INTER- AND TRANSDISCIPLINARITY}

Universities are uniquely poised to produce knowledge to inform decision making for social and environmental change, but this will require transformation in academic cultures (Nisbet, Hixon, Moore, \& Nelson, 2010; Whitmer et al., 2010).

Transdisciplinarity offers frameworks that may help in efforts to reorganize disciplinary research to foster a tighter coupling between science and society, which is a core goal of a transdisciplinary orientation (Klein, 2004; Lang et al., 2012). Korazim-Kõrösy et al. (2007) described cross-cultural conceptualizations of multi-, inter-, and transdisciplinarity in community practice that correspond with discussions of these orientations in actionable science (Gardner, 2012; Jahn, Bergmann \& Keil, 2012; Miller et al., 2008). Drawing from these discussions, we understand interdisciplinary integration "as the cognitive operation that establishes a novel, hitherto nonexistent 
connection between distinct entities of a given context" occurring as a phase within a broader transdisciplinary frameworks (Jahn et al. 2012, p. 3). Within a transdisciplinary process framework, interdisciplinary integration occurs when people with different types of knowledge, value systems, and perspectives on research bring these differences into collaborative settings. The integration occurs not in blending these differences, but when these differences result in new insights, connections, and forms of knowledge (Jahn et al., 2012).

We add to Korazim-Kõrösy et al.'s (2007) list of metaphors about interdisciplinarity drawn from US and Israeli research contexts to offer one that circulates within SSI. We do this with the intention that this metaphor becomes a boundary object, a device that enables learning across perspectives (Nielsen, 2009). For us, interdisciplinarity is not a potluck supper where everyone brings whatever they have and collaborators pick and choose from the best dishes. Instead, interdisciplinary integration is like cooking a meal together from scratch. In this interdisciplinary meal "each vegetable is essential to the ... unique flavor, but each ingredient is still detectable as a carrot or a potato. Each member adds the perspective of one's own discipline. ... Yet each member is able to maintain his or her own identity" (Powell, Dossser, Handron, McCammon, \& Temkin, 1999, p. 39). Thus, cooking a meal in collaboration requires coordination and the combination of different ingredients to produce something fundamentally new but in a way that still holds true to the distinct tastes of those involved in the project.

Key to successful cooking, and by extension research, is a willingness to reflect critically to identify ways to improve processes and outcomes for all involved (Brown, 
2010) and promote the generative potential from difference (McGreavy et al., 2013).

Because power is embedded within and constitutive of any knowledge production

process (Fiki, Amupitan, Dabi, \& Nyong, 2007; Foucault, 1991; Macmynowski, 2007), efforts to erase or overcome difference occur through power. Thus, as our SSI case study and subsequent discussion demonstrates, we work toward maintaining difference while promoting mutual understanding and enhancing the generative capacity emergent from difference. Generative potential in interdisciplinarity is realized through sustained effort and attention to difference; acceptance of the ethical responsibility to reflect critically on power in shared spaces of decision making; and strategic interventions to continually promote and improve learning.

\section{SETTING THE CONTEXT FOR CASE STUDY ANALYSIS}

SSI represents one of the largest, most extensive interdisciplinary efforts to implement an actionable science model (Kates et al., 2001). As the Emmy- award winning films in the series Sustainable Maine by the Maine Public Broadcasting Network (MPBN) demonstrate, SSI research occurs in diverse settings, with diverse partners, focused on diverse problems, all of which address sustainability issues (Ferrel, 2012). Three specific examples of team projects illustrate some of the rich experiences occurring within this collaboration network. In the first project, researchers are working with municipal planners across the state to develop landscape scale strategies to conserve important wetland habitats while minimizing impacts on private property and 
residential development. As part of this collaboration, interdisciplinary team members are devising innovative ways to track amphibians to learn more about their movements across different land cover types, which will inform town and state regulations to more effectively balance conservation and economic development. In another project, collaborators recognized the imminent threat that an invasive insect, the Emerald ash borer, poses to Native American communities. The basket-making culture, origin stories, and resultant livelihoods within these communities depend on the brown ash tree, a species that will disappear if the emerald ash borer reaches Maine forests. Members of this team, including basket-makers and faculty members from diverse disciplines, worked together to create an emergency response plan and adaptive strategies to mitigate this threat. In a final example, the Belgrade Lakes Region is home to waterways that are vital to the ecology of the region, which also supports a tourist-based rural economy and community members' sense of place and history. On this team, natural and social science researchers and historians collaborate with community members to understand the multiple values associated with this resource and make informed decision in the face of changes in landscape development, water quality, and climate.

As these projects demonstrate, $\mathrm{SSI}$ is about aligning research with the needs of communities to ensure that science can inform decision making and lead to more sustainable practices across a range of issues related to landscape change. Bringing together more than 15 disciplines in over 12 higher education institutions, SSI, as a case study, illustrates the challenges of aligning research across disciplines and with community partners. Through our work together, we have also identified ways of 
addressing those challenges.

\section{METHODS IN DIFFERENCE-MAKING RESEARCH}

This case study is informed by research that occurred from November 2010 to March 2013. We interviewed 41 faculty members and graduate students using a purposive and comprehensive sampling strategy that invited participation from University of Maine and University of Southern Maine researchers because these institutions serve as the hub for the initiative (Corbin \& Strauss, 2008; Lincoln \& Guba, 1985; Patton, 2002). Interviews lasted approximately $1 \mathrm{hr}$; audio recordings were fully transcribed, which resulted in more than 600 pages of single-spaced transcripts. We inductively coded transcripts in multiple phases of coding and triangulation among a core team of researchers and students. We also conducted informal participant observations at relevant events including all-team meetings, annual retreats, and multiple workshops. We used participant observations and interviews with key informants (n 5) to member check our interpretations (Lincoln \& Guba, 1985; Patton, 2002). We selected key informants based on their role and position within SSI an organization. We invited participation from select administrators, faculty members, and a student who were involved in multiple teams and cross-project collaborations; represented bio- physical and social science perspectives; and participated in SSI events and learning activities (Lincoln \& Guba, 1985; Patton, 2002). In our discussion of themes from the interviews, we selected comparative quotes to illustrate differences in 
perspective. Although these quotes demonstrate unique perspectives, they are also representative of other instances in which we heard similar statements related to differences and challenges in collaboration.

In this analysis, we draw on results from our qualitative research on interdisciplinarity in SSI to highlight some of the issues that SSI throws into broad relief. As an example, in one interview an SSI faculty member succinctly described the range of differences and the challenges that follow from them:

Well, every possible challenge: different cultures, different values, different beliefs, different institutional contexts, different incentives and disincentives, different languages, different goals. For many faculty, the problems do not look like the beautiful problems that scholars sometimes talk about, but these literally messy wicked problems. And that isn't the path of glory in academia by a long shot.

As this quote demonstrates, differences are central to the SSI experience. We consider four primary differences we observed in SSI, each of which relate directly to the stakes of knowledge production within organizations. We focus in particular on differences in (a) research framing and assumptions about the wickedness of the problem; (b) in how we decide who to involve in research processes; (c) in disciplinary methods and perspectives on what counts as good science; and (d) how to best share knowledge. We begin by describing some of the core differences and as we advance our 
discussion, we introduce specific strategies for encouraging the generative potential from difference, such as the use of boundary objects, specific decision making strategies that promote inclusiveness, and ways to attend to power in the production of knowledge.

HOW WICKED IS YOUR PROBLEM? DIFFERENCES IN UNDERSTANDING CONTEXT AND COMPLEXITY

In our Maine-based context, the concept of a wicked problem is both apt and sticky because this is a commonly used term, an adjective that accentuates what it describes. In a similar vein, the full acronym for SSI is MeSSI (Maine's Sustainability Solutions Initiative). Both of these framing devices ask that we conceptualize our collaborations from the outset as messy and wicked (Kreuter et al., 2004). Paradoxical of wicked problems is that "the nature of the problem is likely to be viewed differently depending on the perspectives and biases of those with a stake in the problem" (Kreuter et al., 2004 , p. 442). Instead of approaching double binds as something we need to resolve to move forward, in this and the subsequent differences described here, we treat paradox and complexity as pathways to new conditions of possibility (Silka, 1999). In this section, we assert that a critical inquiry of differences related to the problem definition, with a particular focus on how researchers understand and set boundaries around the context; define information sources and assess limits; and orient toward particular modes of action from the beginning may help collaborators recognize obstacles and opportunities 
as they are encountered.

The use of computer simulation models is one common method that SSI researchers employ. SSI's funding came from Maine's Experimental Program to Stimulate Competitive Research (EPSCOR), which aligns with the funding priorities in Coupled Natural Human Systems ( $\mathrm{CNH}$ ) division of the National Science Foundation. One of their guiding priorities is the development of computer-based models to reduce uncertainty and improve decision making in the face of complex systems change. The use of computer models in actionable science requires researchers to enter into a process of "co-defining science questions with policy groups and commingling social and natural science perspectives to refine and then address the questions" (Palmer, 2012, p. 6). Although $\mathrm{CNH}$ modeling is not the only approach within actionable science, it is one method to explore fundamental interactions between nature and society that can be particularly relevant for policy maker needs (Kates et al., 2001; Palmer, 2012).

In the special issue of the journal Maine Policy Review, Waring (2012), an SSI researcher, described the use of computer modeling as a wicked tool to address wicked problems. He described three teams using this technique to address sustainability issues related to urban development, watershed and lake level management, and land use planning. As a wicked tool, models offer a clearly bounded approach that can allow a team to evaluate several different alternative scenarios in any given situation. We agree with this characterization about models' potential utility. But, as we are learning on SSI, the use of models in interdisciplinary settings is not as straightforward a process as one might initially assume. Challenges emerge through divergent assumptions about the 
model's utility, validity, and potential data sources.

We contrast two statements that focus specifically on computer modeling made by researchers who readily employ this tool in their work. Although these faculty members share an interest in modeling, they demonstrated divergent perspectives about the utility of modeling and identification of when enough is known. The first researcher expressed frustration about the inability to capture the total complexity of a particular ecological system:

I would do a lot of things differently if I were to approach this again, as with any project. I would pick a smaller problem. I think it is too big and too unwieldy to really solve. There are too many human influences in that [system] to really model it accurately. ... So there is a human element. How do you put that in a computer model?

The second researcher took a different tack in his understanding of complexity and uncertainty:

You know, "All models are wrong. Some are useful," is the old slogan. So, we don't expect that any of these projections will come true. Just that it's a way of saying "Here's the range of possibilities given different scenarios."

In contrast to the first quote, the second researcher took the view that accurate modeling is impossible and, instead, prioritized a model's utility to guide analysis about 
a range of possible scenarios.

These quotes highlight at least three key differences that influence our collaboration using models of all types. First, we see here and in many other instances in SSI, differences in how to judge the knowledge produced through modeling. Second, differences exist in what is believed to constitute a sufficient confirmation of a hypothesis and level of comfort with the accuracy of prediction. Third, differences complicate decisions about selecting and aggregating information to feed into computer simulations. These quotes illustrate a contrast between two researchers who readily employ computer simulation models to highlight that even when researchers may think they have shared frames, such as when they use similar methods, differences still exist. The question of how they decide who to involve, in this case in the development and use of computer simulation models, constitutes another layer of difference to further complicate these processes, a theme to which we now turn.

HOW DO WE DECIDE WHO TO INVOLVE? DIFFERENCES IN DECISION MAKING AND ASSUMPTIONS ABOUT STAKEHOLDERS

Disciplines differ in their assumptions about what constitutes a stakeholder or community partner. These differences about who is believed to have valuable knowledge and when they should be involved add complexity to interdisciplinary partnerships. In this section, we describe differences in how researchers think about stakeholders, involve them in research processes, and assess stakeholder needs. These 
points relate more broadly to differences in orientations toward research processes, products, and decision making strategies and we take this up at the end of this section to offer a concrete strategy to promote mutual learning on assumptions about stakeholders.

The ambiguities and complexities of who is seen as a stakeholder are evident in one SSI researcher's remarks:

I think that in this whole thing the hardest thing for me is: Who are the stakeholders? And I mean my fear is that there are stakeholders that I don't know about (laughs). How do you pick? How do I go out and find a relevant stakeholder? At the end of the day, it's the general public right? ... That's an awful big pool. That's not a single stakeholder by any stretch of the imagination.

This distinction between types of stakeholders raises a series of process- related questions that reveal potential differences in perspectives about the homogeneity of stakeholders as a category, how select stakeholders contribute to solving sustainability problems, views about knowledge generation as a reciprocal process, and the degree to which research decision making is a collaborative process.

Following this sense that defining stakeholders is ambiguous and challenging, other members of the team may have started a sorting process to categorize stakeholders in ways that may not align with how others view these potential participants. As one researcher demonstrates: "So, we have stakeholders that are contributing to the 
research and then we would also have kind of user-stakeholders... We're still unclear about the user- stakeholder, I guess is the term l'll use, versus the co-creator stakeholders." As a yet another take on this distinction between user-stakeholders and co-creator stakeholders, one researcher commented:

Different groups of stakeholders need different kinds of information to make decisions. Policy makers are very data hungry for information on potential environmental impacts. For the community members, there's an element of "having my voice heard in the process." So it means a lot to them to be listened to and feel like their concerns are being heard in the process, that they're not being dismissed and that they have no control of what's going on.

In these quotes, there is an observed tension between research products and research processes. For some, the solution means something recognizable and tangible, like data that can inform policy and decision making. For others, the solution is a process in which different types of stakeholders have a space for democratic inclusion in decision making. But as the first person articulated, if the general public as an allencompassing category can be viewed as a stakeholder, how does one differentiate between those who should be involved at various stages and how best to involve them so that the science produced does, indeed, become actionable?

Differences in defining stakeholders constitute a key site of tension on teams, one that can be heightened or resolved through specific approaches to decision making. We 
have found that some teams use an inclusive consensus-based decision making process.

This type of decision making corresponds with the perspective that one researcher shared that "if something affects you, and you're a part of the team, you should have a say in it." In other teams, researchers adopt a constrained and hierarchical decision making process in which principal investigators have authority over the research-related decisions. Based on our qualitative observations, we see a relationship between approaches to decision making and team outcomes such as mutual understanding, progress toward stated goals, and satisfaction in partnerships. Effective collaboration processes rely on inclusive decision spaces that allow collaborators to engage divergent views (Daniels \& Walker, 2001; Norton, 2007; Woodford \& Preston, 2011). In this example, when collaborators openly address the question of "who do we involve in this research" in a space in which decision making is shared, that space of interaction becomes an opportunity for the team to learn from the differences in how they explicitly and implicitly view stakeholders. Shared decision space becomes a starting point for learning from differences in perspective (Daniels \& Walker, 2001).

Thus, approaches to decision making constitute one pragmatic strategy that can have implications for how teams engage difference. At the same time, consensus-based strategies and efforts to define common ground come with their own forms of exclusion (Cherry \& Shefner, 2005; Reisch, 2012). There is always a need to attend to forms of closure and the circulation of power in knowledge production (Foucault, 1991; Mumby, 2000). As we demonstrate in the following section, this is particularly true for differences in how collaborators conceive of rigor in research and how these evaluations 
prioritize certain aspects of research over others.

HOW GOOD IS YOUR SCIENCE? DIFFERENCES IN PERCEPTIONS ABOUT RIGOR

Disciplinary differences in perceptions about rigor is another area that challenges the success of interdisciplinarity. The SSI experience points to the depths of these differences and illustrates how they translate into contradictions in how worldviews influence the production of research. Conflicting paradigms produce collaboration challenges in and of themselves, but the active process of negotiating what does and does not count as good science also has the potential to create hierarchical power relations that limit individual agency (Gardner, 2013; Macmynowski, 2007; Reich \& Reich, 2006). Here, we assert that attending to differences in our implicit understandings of what constitutes good science opens up an opportunity to also attend to power as it circulates in research processes. This has implications for our identities as interdisciplinary scholars and collaborators.

The following quote from an SSI researcher illustrates one disciplinary view of what constitutes good science and points to some of the core paradigmatic differences within SSI:

Even in a 4-5 year timescale, I'm unsure how rigorously can we attribute improved knowledge partnerships and engagement to action and, then, how quickly can we sort of even quantify the impact. So a lot of this work has longer time horizons to assess success or failure or 
reasonable outputs and outcomes.

Other SSI disciplines treat the knowledge partnerships as crucial to achieving good science and see this process as occurring on more immediate timescales:

I think every situation has to be assessed in its own way. Because I think you also operate on a sort of temporal continuum. ... Time lapses and we need to get feedback on: Did this work, did it not work, why didn't it work, how can we change it? So I think even within a specific situation you have an approach shifting over time.

These quotes highlight differences in how disciplines within SSI understand rigor and what constitutes rigorous method; the role for qualitative, quantitative, and mixedmethods approaches to characterize impacts and outcomes; and the expected time frames associated with when enough is known, a concept that will be expanded on in the subsequent section. The first researcher appears to privilege quantitative methods. For her, rigorous research is a sustained data collection effort leading to a large dataset that can be analyzed over time to detect changes in specific variables. Some researchers might even disagree with this nonexperimental observational approach, arguing that an experimental design is the best way to verify effects and response to specific treatments against a control. Even when SSI researchers agree on the method of data collection, choices around data analysis, such as which types of statistics they find acceptable, constitute another potential difference. 
For some, the words ontology, epistemology, and methodology are core concepts in their disciplinary training. For others, these words constitute jargon that has little to do with the practical nature of conducting fieldwork. In her work on paradigmatic differences within large scale multidisciplinary collaborations, Gardner (2013) argued, "[Taken] together, the concepts of paradigmatic assumptions in inquiry and disciplinary hierarchy create a deeper understanding of some of the challenges inherent in interdisciplinary research collaborations that cross both of these boundaries" (p. 4). She went on to note that differences in how people understand and measure reality go beyond the difficulty in trying to navigate conflicting or unfamiliar language. These differences can manifest themselves in hierarchical power relations in which biophysical sciences have a privileged knowledge position over the social sciences. Thus, "the call for cross cultural competence in inter-disciplinary work is also a call for reflexivity about power within academic institutions and between disciplinary cultures themselves" (Reich \& Reich, 2006, p. 59). Finding ways to negotiate power in interdisciplinary collaboration is essential because knowledge as power has the ability to control and unnecessarily constrain how people come to see themselves as researchers and how then they act in collaborative research processes (Fiki et al., 2007; Foucault, 1972; Macmynowski, 2007).

WHERE DO WE GO FROM HERE? DISCIPLINARY DIFFERENCES IN HOW WE SHARE KNOWLEDGE AND SPAN BOUNDARIES 
Assuming that interdisciplinary researchers can advance through stages of research together to define the research problem and question, design the method, and collect and analyze data to determine when an adequate level of knowledge has been produced for decision making, they must also identify ways to share that knowledge to promote informed decision making and action. In this final section, we highlight differences in how faculty members described communication of their research, with a notable emphasis on whether this is a stage that happens at the end of research or throughout the process. We assert that boundary-spanning literature offers practical strategies to improve the coordination of communication-related activities throughout a research process.

As we have argued, the movement of knowledge into action is central to actionable science models (Kates et al., 2001; Palmer, 2012). This researcher highlights the importance of translating research to make it actionable:

Well, sustainability science doesn't do any of us any good stuff here [points to head]. If I know in my head how to write a model, it doesn't do me any good. I write awesome models, and it still doesn't do any good if I can't communicate them.

Her perspective corresponds with other work in sustainability science that emphasizes the need to attend to communication processes in the translation of science research into action (Cash et al., 2003; Lindenfeld et al., 2012). However, as the following quote demonstrates, we do not necessarily agree on what the action in 
actionable science means:

We're not on the same page SSI-wide or even within our own teams about the expectations of what the action part is.... I think it's really easy to devolve into just, "We have a responsibility to complete this project and to pump out a bunch of publications and satisfy the requirements." We need to figure out what our expectations or objectives are in terms of how much action and whose actions and on what time scale is the action.

This quote highlights the diversity of ways in which faculty members consider communicating results. For this researcher, "pumping out a bunch of publications" does not constitute an effective endpoint for linking knowledge with action. In contrast to the previous model builder, who emphasized finding ways to translate her results so they are meaningful, this person seems to prefer to think about communication throughout the process as a means for translating knowledge into action. This difference may be reflective of disciplinary orientations toward theory building as a "pure" science as compared with disciplines that tend to emphasize practice and engagement in the “applied" sciences (Gardner, 2013, p. 3).

As these quotes demonstrate, there is a need for coordinated sets of practices to effectively engage these and other differences to find ways to work through (Daniels \& Walker, 2001). The use of boundary objects in processes of negotiation, mediation, and translation for improved linkages between knowledge and action is one important strategy to create a space in which differences may be negotiated and collaborators 
may begin to develop a shared understanding (Cash et al., 2003; Clark et al., 2011).

Discussions of boundary-spanning processes, such as those that occur when faculty members work across disciplines, tend to focus on the development of shared frameworks (Clark et al., 2011) and activities (Weerts \& Sandmann, 2010; Whitmer et al., 2010). These strategies are intended to facilitate common language and coordinated approach. For example, the Consultative Group on International Agricultural Research has used various approaches to boundary work (Clark et al., 2011). Of the boundaries that formed among disciplines, Clark et al. (2011) noted, "Differences among disciplines in jargon and rules of evidence, plus an initial lack of mutual respect, made the creation of knowledge judged to be credible by all seem almost beyond reach" (p. 3). For each of these boundaries, they identify key considerations in the participation, accountability, and boundary objects that may facilitate boundary crossing. Importantly for the discussion of models as possible boundary objects, "the joint creation of tangible products by scientists and farmers played a significant role in linking research with action. ... Drawings, maps, and physical models of relevant landscapes were the most valued knowledge products" (p. 4). In their experience, shared creation of knowledge products like models was essential to the success of their efforts to link knowledge with action.

Getting on the same page when it comes to communicating the outcomes of research and moving knowledge into action seems to require a commitment to working through these and many other differences that may emerge in collaboration. Approaching the development of models and other research activities from the outset 
as boundary processes in which researchers acknowledge the multiplicity of

perspectives and the contingency of all knowledge may create the kind of space required to realize the creative potential that bringing together difference promises.

Direct attention to boundaries may also help researchers pay continual attention to power as it circulates in their knowledge production processes and work toward making those processes as equitable as possible (Cherry \& Shefner, 2005; Clark et al., 2011). In the next section we continue and expand this discussion of boundary objects as one key strategy in a portfolio of approaches to promote the productive potential from difference.

\section{DISCUSSION AND RECOMMENDATIONS}

We drew from SSI throughout this article to illustrate the common challenges that emerge when diverse disciplines attempt to work together and with communities on wicked problems. The SSI experience highlighted four key differences among disciplines that can thwart effective collaborations: disciplinary differences (a) in framing issues and grappling with complexity, (b) in decision making and stakeholder involvement, (c) in assumptions about what constitutes rigorous science, and (d) in communicating the results of research. Disciplines hold vastly different views on the aforementioned issues and, as the SSI makes explicit, it is not until researchers attempt to work directly together that the discrepancies in practices become apparent. As we have shown, these are not trivial issues. They go to the very heart of what different kinds of researchers 
take to be the gold standard of good science.

This article has analyzed the intricacies of these issues to bring home the point that differences among disciplines present both challenges and opportunities. If disciplines are encouraged to work together but structures and practices are not in place to facilitate such collaborations, then the collaborative work will likely fail. Such attempts will be short lived as disciplines revert back to disciplinary silos (Silka, 2013). The SSI experience points to some clear recommendations, some of which we started to develop earlier and carry forward here, for strengthening team-based and interorganizational collaboration. We return to our metaphor of making dinner to organize four specific recommendations, including: (a) think about power in the kitchen,(b) attend to decision making about the meal, (c) seek and create opportunities to learn more about cooking, and (d) write down your recipes as a way to explore differences. The first two recommendations are best taken together, as decision making and power clearly mutually influence each other (Breton, 2004; Norton, 2007). These recommendations also implicitly consider core components of inter-organizational collaboration such as leadership, membership, purpose, strategies, structure, tasks, and systems that emerge from the interaction of these components (Bailey \& Koney, 1995).

Think About Power in the Kitchen

If you have ever tried to cook in a power outage, you know what a difficult task this can be. Power is productive: of knowledge, of identities, of research collaborations, of 
the myriad contexts in which human beings engage in world making work (Fiki et al., 2007; Foucault, 1991). Decision making is one expression of power in the collaboration. Those who do not have access to the decision space do not have equal power (Norton, 2007; Senecah, 2004). Although in the following we note the importance of inclusive decision making approaches like consensus models, we also recognize that in situations characterized by power disparities, other decision making approaches, such as conflict or two-phase deliberation models, may be more appropriate (Cherry \& Shefner, 2005; Reisch, 2012). Regardless of the situation, interdisciplinary collaboration requires a degree of organizing team members and attending to power and decision making directs attention to the social effects of this organizing.

The intentional use of boundary objects offers one strategy for attending to power and decision making. We introduced the use of boundary objects previously and return to it here because boundary objects function at two levels. In the example we described, the use of models as boundary objects may produce mutual understanding and help facilitate communication at a pragmatic level. However, boundary objects also participate in the simultaneous production of knowledge and social order and in doing so they function as an object of power (Guston, 2001; Jasanoff, 2004). When collaborators strategically use boundary objects, attending to the pragmatic and constitutive dimension of their use invites continual attention to how power circulates in collaborative processes. Being aware of this tension is a first step in identifying contextually appropriate strategies to promote equity in process (Cherry \& Shefner, 2005; Clark et al., 2011). 
Attend to Decision Making About the Meal

Decision making as a space of interaction on interdisciplinary teams enables collaborators to identify and work through differences as they emerge (Daniels \& Walker, 2001). In advancing an empowerment model of group process, Breton (2004) argued that it is essential for all group members to have "the opportunity to share power to define what the group will be about and what it will do.... Participating in that process also establishes that decision making in the group will be democratic" (p. 61). This emphasis corresponds with discussions of voice and agency in public participation processes (Norton, 2007; Senecah, 2004)

Decision making contexts where one person-often the leader of the research team-makes all of the research-related decision hinders interdisciplinary integration, and creative opportunities that emerge from difference become highly constrained. In these situations, differences in perceptions about the wickedness of the problem, the definition of stakeholders, the standards for rigorous research, and how best to communicate the results of research still exist, but the inability to articulate them closes down the opportunity for these differences to generate novel insights. As a consequence, collaborators may feel disempowered from the outset, and differences may persist as challenges turn into barriers and result in the eventual disintegration of the research partnership. This does not mean that every individual on the team must exercise decision authority, as clear leadership promotes effective collaboration (Bailey 
\& Koney, 1995). Instead, members of the team need voice and agency to participate in the decision making process (Breton, 2004; Norton, 2007; Senecah, 2004).

Create Opportunities to Learn How to Cook Together Better

In SSI, we have worked toward becoming reflective practitioners by using boundary objects and other strategies, as we described. We have repeatedly turned to the empirical literature on boundary spanning for guidance. As one example, we found that offering a graduate course on boundary spanning was an effective strategy for creating a place for us to collectively consider practices such as the creation of boundary objects to enhance collaboration. The interdisciplinary mix of faculty members who taught this course also invited boundary spanners from within and outside academia who shared their experiences for enhanced learning among students, faculty, and current and potential collaborators.

From this and other experiences, we recommend developing strategic learning events based on recommendations in boundary spanning and other practice-oriented literatures (Dewulf et al., 2007; Thompson, 2009; Winowiecki et al., 2011). In SSI, we created science communication workshops that modeled boundary spanning strategies and focused on framing techniques to support the MPBN series mentioned previously. We facilitated discussion sessions that used boundary objects, such as maps, and boundary- spanning activities like World Café-style discussions, and visual graphic recording. We created multiple informal workshops that opened a space for talking 
about opportunities and complexities in working together and learning from

stakeholders. These learning events provided an opportunity for sharing information; they also helped group members form relationships within and across teams in the organization. This latter function has been shown to be important in the overall effectiveness of community interventions (Reisch, 2012) and may also provide the discursive resources to promote specific community identities (Colombo \& Senatore, 2005; Giddens, 1984).

Write Down Your Recipes as a Way to Explore Differences

Personal, professional, and institutional factors can present challenges in interdisciplinary collaboration (Powell et al., 1999). The amount of time collaboration takes is held in tension with time demands for successful tenure and promotion. Faculty members often worry that efforts to create interdisciplinary partnerships will carry such high transaction costs that their written output and production will suffer. To address this concern, we combined our focus on strengthening interdisciplinarity with targeted writing. Strategic writing projects were designed that brought together a portfolio of projects and specifically encouraged SSI teams to analyze and reflect on the ways they are directing their efforts toward overcoming disciplinary and partnership obstacles (Silka, McGreavy, Cline, \& Lindenfeld, 2012). These efforts led, for example, to a full issue of Maine Policy Review (http://mcspolicycenter.umaine.edu/reportspublications/maine-policy-review/mpr21- 
$1 /)$, a journal read by many constituents in Maine, including legislators and other policy makers, that brought interdisciplinary teams together to reflect on and move forward their inter- disciplinary efforts. This enabled better team communication and created an opportunity to share project learning with important audiences across the state. We recommend that teams working toward overcoming disciplinary differences in their community partnerships find ways to combine the goals of partnership and publication as a potentially powerful way to harness creativity in difference.

\section{CONCLUSION}

Actionable science and community practice share a commitment to solving complex problems for change in diverse social and environmental contexts (Butterfield \& Korazim-Kõrösy, 2008; Palmer, 2012; Weil et al., 2013). Moving forward will require many attempts, large scale and small, that test strategies for bringing disciplines together with community partners in innovative ways. We offer these recommendations as a pragmatic set of considerations based on our experience within SSI. Although strategies will necessarily differ depending on context (Clark et al., 2011), the commitment to understanding differences emergent in collaboration remains constant.

Our point, in the end, is to argue that interdisciplinary collaboration represents a daunting challenge that exposes and enhances some of the wickedness in contexts characterized by complex sustainability-related challenges. But even more important, 
when approached thoughtfully and strategically, differences inherent in collaborations may turn into sources of creative insight and unseen potential. The differences we illustrated in methodological issues related to problem framing, identifying collaborators, defining standards for rigor, and communicating results of research serve as an anchor point for taking up even more challenging differences related to how we see the world and perform ourselves within it (Dewulf et al., 2007). Attending to these and other differences in collaboration processes based on shared decision making, continual reflection on power, and that use activities to promote mutual understanding contribute to making a meal that will be more sustainable and satisfying for all who partake.

FUNDING AND ACKNOWLEDGMENTS

We acknowledge and thank the Sustainability Solutions Initiative faculty and graduate students who contributed their insights to this research. This research was made possible through a National Science Foundation award EPS-0904155 to Maine EPSCoR at the University of Maine. 
REFERENCES

Bailey, D., \& Koney, K. M. (1995). An integrative framework for the evaluation of community-based consortia. Evaluation and Program Planning, 18, 245-252. doi:http://dx.doi.org/10.1016/S0149-7189(95)00019-4

Bayne-Smith, M., Mizrahi, T., \& Garcia, M. (2008). Interdisciplinary community collaboration: Perspectives of community practitioners on successful strategies. Journal of Community Practice, 16, 249-269.

Breton, M. (2004). An empowerment perspective. In C. D. Garvin, L. M. Gutierrez \& M. J. Galinsky (Eds.), Handbook of social work with groups (pp. 58-75). New York, NY: Guilford.

Brown, V. A. (2010). Can there be a community of practice? In V. A. Brown, J. Harris \& J. Russell (Eds.), Tackling wicked problems: Through the transdisciplinary imagination. (pp. 285-297). Washington, D.C.: EarthScan.

Butterfield, A. K. J., \& Korazim-Kõrösy, Y. (2008). Interdisciplinary community development. Journal of Community Practice, 15(1-2), 239-245.

Cash, D., Clark, W. C., Alcock, F., Dickson, N. M., Eckley, N., Guston, D. H., Mitchell, R. B. (2003). Knowledge systems for sustainable development. Proceedings of the National Academy of Sciences of the United States of America, 100, 8086-8091.

Cherry, D. J., \& Shefner, J. (2005). Addressing barriers to university- community collaboration. Journal of Community Practice, 12(3-4), 219-233.

doi:10.1300/J125v12n03_13

Clark, W. C., Tomich, T. P., van Noordwijk, M., Guston, D., Catacutan, D., Dickson, N. M., \& McNie, E. (2011). Boundary work for sustainable development: Natural resource management at the Consultative Group on International Agricultural Research (CGIAR). Proceedings of the National Academy of Sciences of the United States of America. doi:10.1073/pnas.0900231108

Colombo, M., \& Senatore, A. (2005). The discursive construction of community identity. Journal of Community \& Applied Social Psychology, 15(1), 48-62. doi:10.1002/casp.809

Corbin, J., \& Strauss, A. (2008). Basics of qualitative research (3rd ed.). Thousand Oaks, CA: SAGE.

Daniels, S., \& Walker, G. B. (2001). Working through environmental conflict: The collaborative learning approach. Westport, CT: Praeger.

Dewulf, A., François, G., Pahl-Wostl, C., \& Taillieu, T. (2007). A framing approach to cross-disciplinary research collaboration: Experiences from a large-scale research project on adaptive water management. Ecology and Society, 12, 1-24.

Ferrel, F. (Director). (2012). Sustainable Maine. Bangor, ME: Maine Public Broadcasting Network.

Fiki, C. O., Amupitan, J., Dabi, D., \& Nyong, A. (2007). From disciplinary to interdisciplinary community development: The Jos-McMaster drought and rural water use project in Nigeria. Journal of Community Practice, 15(1/2), 147-170.

Foucault, M. (1972). The archaeology of knowledge: And the discourse on language. 
New York, NY: Random House.

Foucault, M. (1991). Governmentality. In G. Burchell, C. Gordon \& P. Miller (Eds.), The Foucault Effect: Studies in Governmentality: With Two Lectures and an Interview with Michel Foucault (pp. 87-104). Chicago, IL: University of Chicago Press.

Gamble, D. N., \& Hoff, M. D. (2013). Sustainable community development. In M. Weil, M. Reisch \& M. L. Ohmer (Eds.), The handbook of community practice (2nd ed., pp. 948). Los Angeles, CA: SAGE.

Gardner, S. K. (2012). Paradigmatic differences, power, and status: A qualita tive investigation of faculty in one interdisciplinary research collaboration on sustainability science. Sustainability Science, 8(2), 241-252. doi:10.1007/s11625012-0182-4

Giddens, A. (1984). The constitution of society: Outline of the thoery of structuration. Berkley, CA: University of California Press.

Guston, D. H. (2001). Boundary organizations in environmental policy and science: An introduction. Science, Technology \& Human Values, 26(4), 399-408.

Gutiérrez, L. M., Lewis, E. A., Dessel, A. B., \& Spencer, M. (2013). Principles, skills, and practice strategies for promoting multicultural communication and collaboration. In M. Weil, M. Reisch \& M. L. Ohmer (Eds.), The handbook of community practice (2nd ed., pp. 445-460). Los Angeles, CA: SAGE.

Jahn, T., Bergmann, M., \& Keil, F. (2012). Transdisciplinarity: Between mainstreaming and marginalization. Ecological Economics, 79, 1-10. doi: 10.1016/j.ecolecon. 2012.04.017

Kates, R. W., Clark, W. C., Corell, R., Hall, J. M., Jaeger, C. C., Lowe, I., Riordan, T. O. (2001). Sustainability science. Science, 292, 641-642.

doi:10.1126/science.1059386

Klein, J. T. (2004). Prospects for transdisciplinarity. Futures, 36, 515-526. doi:http:// dx.doi.org/10.1016/j.futures.2003.10.007

Korazim-Kõrösy, Y., Mizrahi, T., Katz, C., Karmon, A., Garcia, M. L., \& Smith, M. B. (2007). Towards interdisciplinary community collaboration and development. Journal of Community Practice, 15(1-2), 13-44.

Kreuter, M. W., Rosa, C. D., Howze, E. H., \& Baldwin, G. T. (2004). Understanding wicked problems: A key to advancing environmental health promotion. Health Education \& Behavior: The Official Publication of the Society for Public Health Education, 31, 441-454. doi:10.1177/1090198104265597

Jasanoff, S. (2004). Ordering knowledge, ordering society. In S. Jasanoff (Ed.), States of Knowledge: The Co-Production of Science (pp. 25-98). New York, NY: Routledge.

Lang, D. J., Wiek, A., Bergmann, M., Stauffacher, M., Martens, P., Moll, P., Thomas, C. J. (2012). Transdisciplinary research in sustainability science: practice, principles, and challenges. Sustainability Science, 7(S1), 25-43. doi:10.1007/s11625-011-0149-x

Lincoln, Y. S., \& Guba, E. G. (1985). Naturalistic inquiry. Newbury Park, CA: Sage. Lindenfeld, L. A., Hall, D. M., McGreavy, B., Silka, L., \& Hart, D. (2012). Creating a place for environmental communication research in sustainability science. Environmental Communication: A Journal of Nature and Culture, 6(1), 23-43. 
doi:10.1080/17524032.2011.640702

Macmynowski, D. P. (2007). Pausing at the brink of interdisciplinarity: Power and knowledge at the meeting of social and biophysical science. Ecology And Society, 12(1), 1-15.

McGreavy, B., Hutchins, K., Smith, H., Lindenfeld, L., \& Silka, L. (2013). Addressing the complexities of boundary work in sustainability science through communication. Sustainability, 5, 4195-4221. doi: 10.3390/su5104195

Miller, T. R., Baird, T. D., Littlefield, C. M., Kofinas, G., Chapin, F. S., \& Redman, C. L. (2008). Epistemological pluralism: Reorganizing interdisciplinary research. Ecology and Society, 13(2), 1-17.

Nielsen, K. H. (2009). In quest of publicity: the science-media partnership of the Galathea Deep Sea Expedition from 1950 to 1952. Public Understanding of Science, 18(4), 464-480. doi:10.1177/0963662507083529

Nisbet, M. C., Hixon, M. A., Moore, K. D., \& Nelson, M. (2010). Four cultures: New synergies for engaging society on climate change. Frontiers in Ecology and the Environment, 8, 329-331. doi:10.1890/1540-9295-8.6.329

Norton, T. (2007). The structuration of public participation: Organizing environmental control. Environmental Communication: A Journal of Nature and Culture, 1, 146170. doi:10.1080/17524030701642546

Palmer, M. A. (2012). Socioenvironmental sustainability and actionable science. BioScience, 62(1), 5-6. doi:10.1525/bio.2012.62.1.2

Patton, M. Q. (2002). Qualitative research and evaluation methods (3rd ed.). Thousand Oaks, CA: Sage.

Powell, J., Dosser, D., Handron, D., McCammon, S., Temkin, M. E., \& Kaufman, M. (1999). Challenges of interdisciplinary collaboration: A faculty consortium's initial attempts. Journal of Community Practice, 6(2), 27-48.

Reich, S. M., \& Reich, J. A. (2006). Cultural competence in interdisciplinary collaborations: A method for respecting diversity in research partnerships. American Journal of Community Psychology, 38, 51-62. doi:10.1007/s10464-0069064-1

Reisch, M. (2012). Intervention with communities. In C. A. Glisson, C. N. Dulmus \& K. M. Sowers (Eds.), Social work practice with groups, communities, and organizations: evidence-based assessments and interventions (pp. 81-130). Hoboken, NJ: Wiley.

Senecah, S. L. (2004). The trinity of voice: The role of practical theory in planning and evaluating the effectiveness of environmental participatory processes. In S. P. Depoe, J. W. Delicath \& M. F. A. Elsenbeer (Eds.), Communication and public participation in environmental decision making (pp. 13-33). Albany, NY: State University of New York Press.

Silka, L. (1999). Paradoxes of partnerships: Reflections on university-community collaborations In N. Kleniewski \& G. Rabrenovic (Eds.), Research in Politics and Society: Community Politics and Policies (Vol. 7, pp. 335-359). Stamford, CT: JAI Press.

Silka, L. (2013). "Silos" in the Democratization of Science. International Journal of 
Deliberative Mechanisms in Science (DEMESCI), 2(1), 1-14.

Silka, L., McGreavy, B., Cline, B., \& Lindenfeld, L. (2012). Introduction. Maine Policy Review, Special Issue: Sustainability, 21(1), 10-13.

Thompson, J. L. (2009). Building collective communication competence in interdisciplinary research teams. Journal of Applied Communication Research, 37, 278-297. doi:10.1080/00909880903025911

Waring, T. (2012). Wicked tools: The value of scientific models for solving Maine's wicked problems. Maine Policy Review, Special Issue: Sustainability, 21(1), 30-39.

Weerts, D. J., \& Sandmann, L. R. (2010). Community engagement and boundaryspanning roles at research universities. Journal of Higher Education, 81(6), 632657.

Weil, M., Reisch, M. S., \& Ohmer, M. L. (Eds.). (2013). The handbook of community practice (2nd ed.). Los Angeles, CA: SAGE.

Whitmer, A., Ogden, L., Lawton, J., Sturner, P., Groffman, P. M., Schneider, L., Killilea, M. (2010). The engaged university: Providing a platform for research that transforms society. Frontiers in Ecology and the Environment, 8, 314-321. doi:10.1890/090241

Winowiecki, L., Smukler, S., Shirley, K., Remans, R., Peltier, G., Lothes, E., Alkema, L. (2011). Tools for enhancing interdisciplinary communication. Sustainability: Science, Practice, \& Policy, 7, 74-80.

Woodford, M. R., \& Preston, S. (2011). Developing a strategy to meaningfully engage stakeholders in program/policy planning: A guide for human services managers and practitioners. Journal of Community Practice, 19, 159-174. doi:10.1080/10705422.2011.571091 